\title{
Creating a Space for Innovative Learning: The Importance of Engaging the Users in the Design Process
}

\author{
Bodil Bøjer
}

\begin{abstract}
Based on an empirical case study, this chapter puts forward the thesis that in order for an innovative learning environment (ILE) to work as intended, three things must be aligned: teaching (the teacher), space (the designer) and organisation (the school management). Ideally, when designing new ILEs all three factors are considered in the design process in order to ensure a common goal: creating the best space for innovative learning. In reality, this rarely happens and the users are left with a physical learning environment where the intentions do not always match educators' expectations and established practices. To remedy this dilemma, the chapter proposes an additional activation phase in the design process after implementation - that is, the early use phase of a new build-where the intentions of the space are translated into actions, and refinements negotiated through discussions with the users through a participatory process. The purpose of this phase is to match pedagogies with spatial possibilities. The methodology used is Research through Design.
\end{abstract}

\section{Introduction}

Space shapes us but we are also affected by the way we interact with and act within the space. Within learning environment contexts, the interdependence between the physical space, innovative teaching and the organisation of a school is often overlooked when designing ILEs. This may be because there are often expectations that a new spatial design will automatically change the way we teach and learn. However, we know that simply changing the space is not enough (Imms \& Byers, 2017); the intentions of the space can only be fully realised if the users of the learning environments are aware of and support the pedagogical principles informing the provision of these spaces (Burke, 2016). Unfortunately, the pedagogies that a project is expected to facilitate often remain unstated, or may even be unknown by those who are to use the facilities (Jamieson, Fisher, Gilding, Taylor, \& Trevitt, 2000).

\footnotetext{
B. Bøjer ( $\varangle)$

Institute of Visual Design, The Royal Danish Academy of Fine Arts, Schools of Architecture, Design and Conservation (KADK) and Rune Fjord Studio, Copenhagen, Denmark e-mail: bobo@kadk.dk
}

W. Imms and T. Kvan (eds.), Teacher Transition into Innovative Learning Environments, https://doi.org/10.1007/978-981-15-7497-9_4 
Blackmore, Bateman, Loughlin, O’Mara, \& Aranda (2011) argue the way a building is inhabited is at least as important as the quality of its design. But on this, there is no convincing body of research that proves any causal link between a new learning space and pedagogic change (Mulcahy, Cleveland, \& Aberton, 2015); space and furnishing do not automatically lead to certain actions or learning processes. That is because such change is mostly about relationships and changing cultures and practices (Blackmore et al., 2011). Arguably, the use of space depends on the receiver (Kirkeby, 2006) and the organisation of the school. Beghetto \& Kaufman (2014) point out that the organisation of, or leadership within a school plays a key role in establishing an environment supportive of creativity, which is why just changing the physical settings or pedagogical methods does not guarantee innovative learning. A good learning environment requires congruence between physical space, pedagogical practices and the organisation of the school (Ricken, 2010).

In this chapter, an ILE is understood to be the combination of an innovative space that supports a wide range of learning needs and situations, often through the provision of a highly flexible interior and purpose-built furniture and innovative teaching and learning. The terms 'innovative teaching' and 'innovative learning' are used throughout this chapter to denote teaching and learning activities that in combination and through their focus on deep-learning foster the so-called 'Twentyfirst Century learning skills' of creativity, collaboration, communication and critical thinking in students and assist in the best possible student learning outcomes, as explained by Mahat, Bradbeer, Byers, and Imms (2018). Hence, innovative teaching and learning strategies are about engaging the students in situated and inquiry-based learning, allowing for experimentation and immersion in subjects of interest (Tanggaard, 2014). The physical design of ILEs range from large open spaces to highly flexible arrangements of classrooms that can be reconfigured into different kinds of learning spaces (Imms, Mahat, Byers, \& Murphy, 2017). Imms and Byers (2017) describe three types of learning spaces that are found in many educational institutions today:'formal' or traditional classrooms focused on largely didactic pedagogies, student-centred spaces focused on transactional approaches to instruction and a 'third space', where social activities overlap informal and active learning activities. These new learning environments provide the infrastructure to inspire teachers to reconceptualise and rethink their teaching. It seems clear that ILEs require a new way of teaching (Imms, Cleveland, \& Fisher, 2016) due to their particular spatial layouts that do not support 'classical' teacher-centred teaching. Instead, ILEs provide a physical setting for collaboration, experimentation and exploration, which are central activities (amongst others) in learning processes that foster creativity and innovation (Craft, 2005; Cropley, 2001; Tanggaard, 2014). 


\section{A Participatory and Practice-Based Research Approach}

Designers tend to be separated from the final users of the physical environment by facility management professionals, which makes the renegotiation of architecturepedagogy assumptions quite difficult, according to Jamieson et al. (2000). However, to establish the best conditions for innovative learning, it is my thesis that alignment between teaching (the teacher), space (the designer) and organisation (school management) is necessary, as illustrated in Fig. 1.

To create this alignment, I propose a participatory form of design processes where both users (teachers and students) and school management are included in the design process regularly to align needs, wishes and intentions continuously in order to assure ownership and use of the space. Blackmore et al. (2011), drawing on Higgins, Hall, Wall, Woolner, and McCaughey (2005) and others, emphasise that 'participatory or generative design involving students and teachers needs to continue throughout all phases - from design to evaluation - in order to achieve sustainable impact within a rapidly changing context' (p. 37). User involvement tends to improve the understanding of needs, resulting in a more suitable building (Clark, 2010; cited in: Könings, Bovill, \& Woolner, 2017). I will elaborate on this in the following chapter, based on a specific case where a new ILE was designed at a municipal primary and lower secondary school near Copenhagen, Denmark in collaboration with the design agency Rune Fjord Studio. To maintain the privacy of the employees and students the school is only referred to as the municipal school.

The research approach used in this particular case is Research through Design (RtD), which allows the researcher to generate new knowledge through processes that simultaneously develop, test and improve design in relation to a specific spatial environment. The role of the designer is thereby merged with the role of the researcher. The methodology of RtD was first described by Christopher Frayling in 1993 and covers a research approach where the design process in itself becomes a way to

Fig. 1 An alignment between teaching (the teacher), space (the designer) and organisation (the school management) is necessary in order to establish the best conditions for innovative learning. Diagram by Rune Fjord Studio

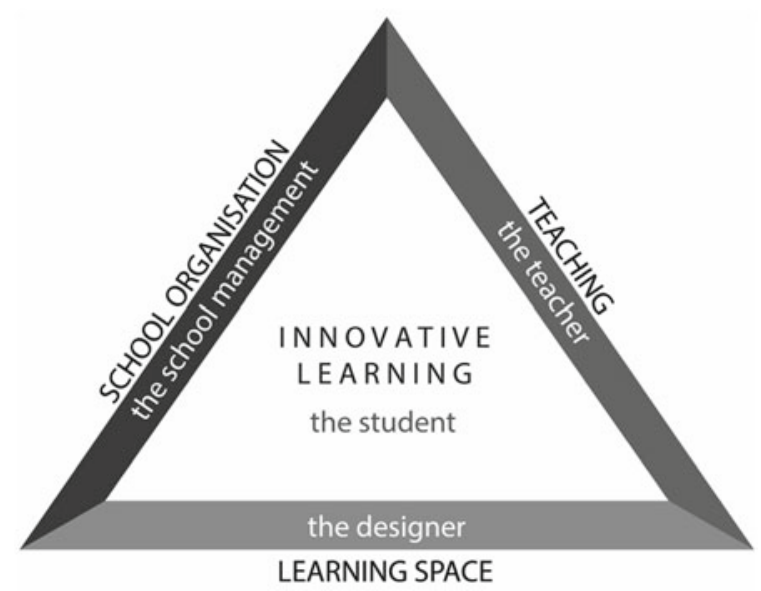


acquire new knowledge. RtD investigates the research inquiry from the practitioner's methods and acknowledges practice as a means of gaining new knowledge, which in this project means developing concrete spatial environments while working in an iterative dialogue with a physical material and the users that reflect back on the research. Research reflections are generated in action (Schön, 1983) through the design process and concrete design proposals.

\section{The Assignment and the Intentions of the New ILE}

In 2016, the design company Rune Fjord Studio was asked to design an ILE in a street-space connecting classrooms used by 3rd to 5th-grade students at a municipal school in Copenhagen, Denmark. The street-space can be explained as an open learning space, big enough for activity and circulation, that cannot be closed into classrooms and is exposed to major traffic as the primary access to other learning spaces (Dovey \& Fisher, 2014). The new premise was as for this development to be used for both formal and informal learning and free play during regular school hours and after school activities, which meant that it had to cover many different functions and transform easily.

Jamieson, Dane and Lippman (2005) claim that spaces outside the classroom cease to exist as transition spaces and become learning spaces in their own rights when they are layered for different ways of learning. Learning environments outside the classroom tend to be less constrained by the educational traditions and habits that often reign in the classroom, I would argue. Transformed into a layered environment with various workstations, these spaces potentially provide opportunities for promoting individual, one-to-one, small group and large group activities where the student takes on a more active role in the learning process. According to research, certain pedagogical strategies allow the students to actively engage in the learning process and become immersed in a topic of interest over a longer time as well as experiment, play and examine open-ended problems promote critical thinking and help develop creative and innovative skills (e.g. Craft, 2005; Cropley, 2001; Tanggaard, 2014). To support this, the space was redesigned with different activity zones, flexibility and diversity in workstations that allow for many types of activities and learning styles as opposed to the original interior consisting only of groups of chairs and tables (see Figs. 2, 3, 4 and 5). A set of purpose-built furniture aimed at supporting the needs and ideas of this particular school as well as innovative learning was especially developed for the space. This included two transformable co-creation cabinets designed as potential tools in innovative processes, one as a mobile design studio and the other as a tool for presentation (see Fig. 6). 


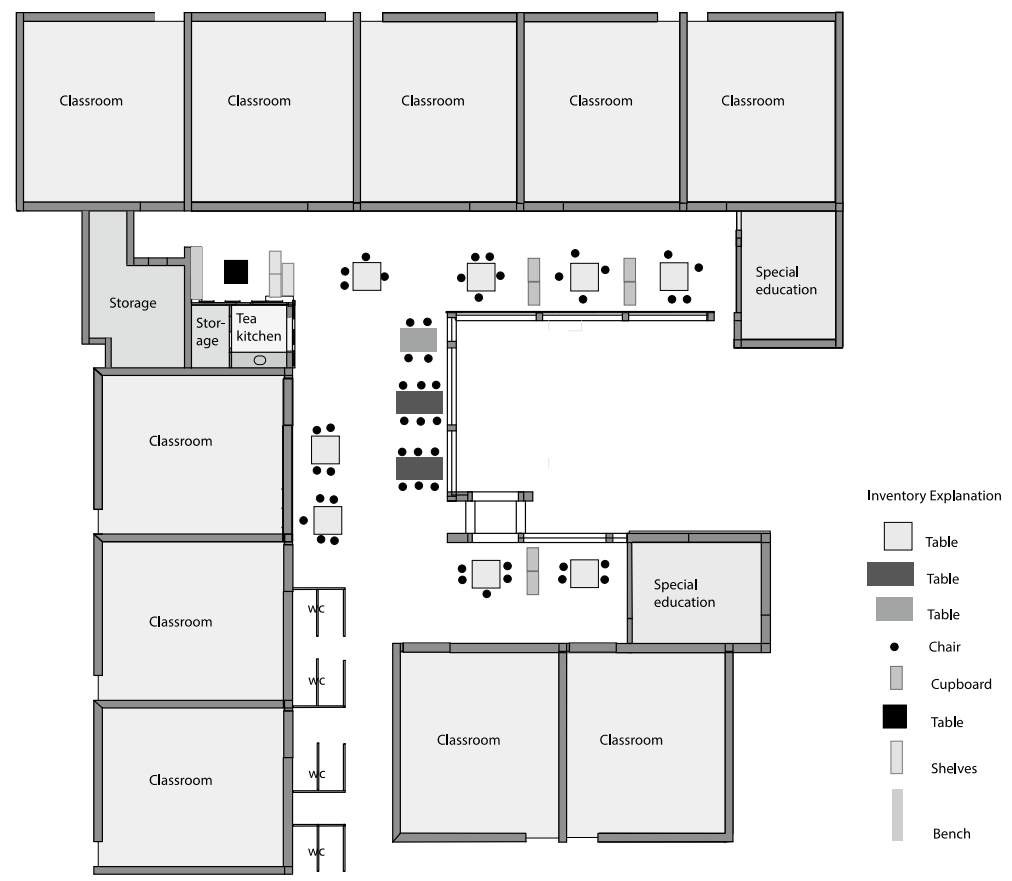

Fig. 2 The original learning environment at the municipal school. Drawing by Rune Fjord Studio

\section{A Participatory Design Process to Align Teaching, Space and Organisation}

The triad of relations between teaching (teacher), space (designer) and organisation (school management) served as the starting point for the design process of the new ILE. A graphic diagram of the design process, inspired by the Double Diamond model by the British Design Council (Council, 2007), served as a tool to keep track of when to involve the different stakeholders in the project. The diagram visualised the four phases of the design process (see Fig. 7), Understand \& Discover, Analyse $\&$ Define, Develop \& Design and Production \& Implementation, which respectively opened and closed the process through divergent and convergent thinking (for more information about design processes see for example Lawson, 2006).

The intentions were to involve all key stakeholders directly or indirectly during the design process on a regular basis. In reality, this was not possible because of budgets, tight deadlines and teachers' workloads. Könings et al. (2017) describe how participation in the design of learning environments is crucial in order to account for the different expectations and perceptions of stakeholders, but might be limited by contrasting expertise, cultures and priorities — or in this case, project restrictions and other circumstances. 


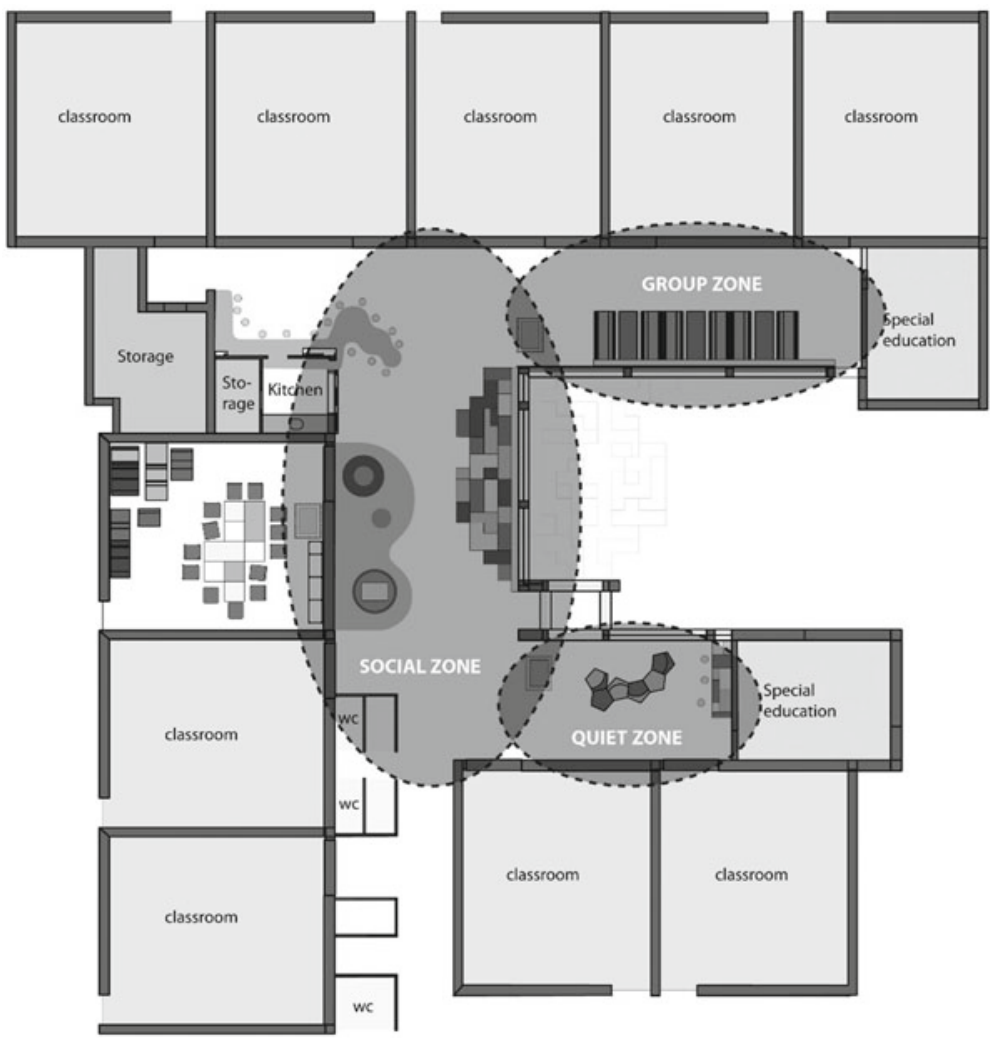

Fig. 3 The innovative learning environment at the municipal school, divided into 3 activity zones: Quiet Zone, Social Zone and Group Zone with a diversity of workstations and flexible furniture. Drawing by Rune Fjord Studio

Initial insights into the needs, wishes, organisation and pedagogies of the municipal school were obtained from the school management prior to the design process, and regular communication between school management and designers were held throughout the project. In addition to this, ethnographic methods such as photomapping and observations were performed during the pre-design phase to collect empirical data that served as a groundwork for the spatial design.

Most user involvements took place during the first phase in which two workshops were held with a group of users to collect information that could lay the foundation for the designing of the space. Only one teacher, two pedagogues (the teachers working in the afterschool club) and school management participated in the first workshop (all teachers were invited) and approximately 30 students and parents took part in the second workshop. The other teachers were informed about the design process regularly by the school management with an invitation to comment on the design but had no direct contact with the designers. 


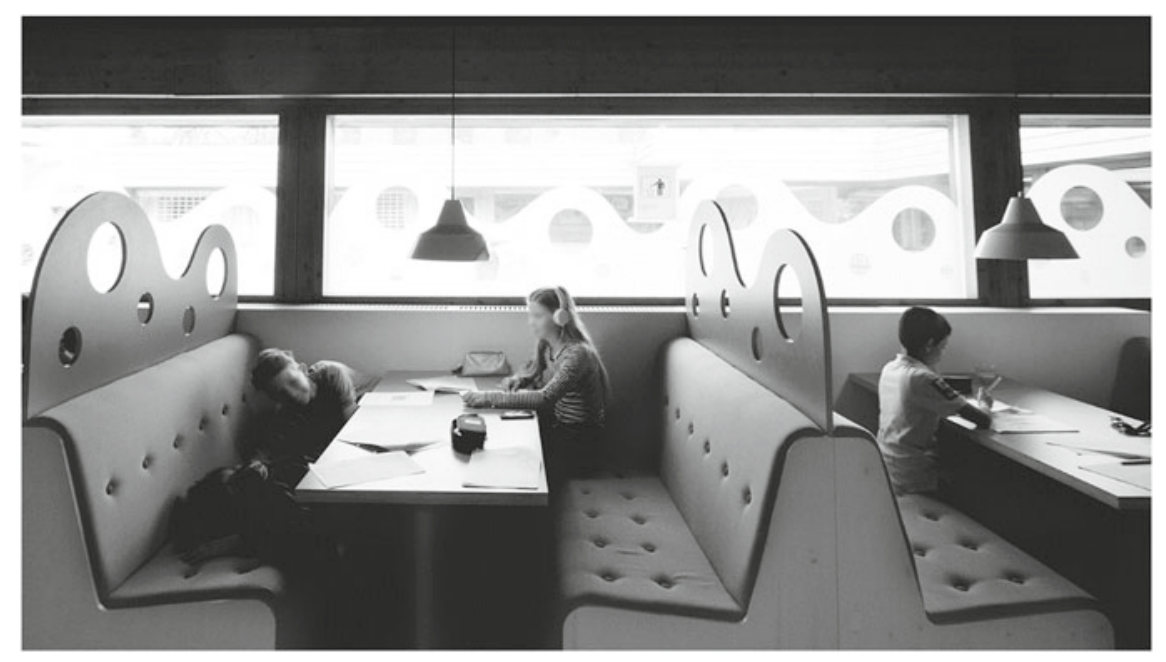

Fig. 4 Diners for collaborative work in the group zone. Photographer: Filipa Pita, Rune Fjord Studio

\section{Without Keys the Spaces Are Hard to Unlock}

The ILE at the municipal school was designed as an active street-space, connecting the nine classrooms with the rest of the school and the outside playground. This typology, where classrooms still play the main part in the teaching and learning situations, arguably requires less from the teachers in terms of changed pedagogies compared to open-plan learning spaces. Still, the teachers in this case experienced a high level of difficulty adjusting to the possibilities and limitations of the new space (personal communication, 17 Aug, 7 Nov, 11 Nov 2017), which will be explained further in the following sections. In contrast to this, the students intuitively adapted to the possibilities of the ILE, choosing freely amongst workstations when given the chance (vice-principal, personal communication, 13 June 2017).

Three months after implementation the designers returned to observe the use of the ILE and experienced a large variation in how much space was used by the different classes. Whereas one teacher took advantage of the variety of workstations in the ILE by working in a dynamic flow between the classroom and the ILE, others stayed inside the classroom for the whole day or used it sporadically. The transformable co-creation cabinets remained unused.

Subsequently, the designers met with the teaching team during one of their monthly departmental meetings to discuss and evaluate the intentions behind the design. During this meeting, the designers discovered that not only were many teachers unaware of the intentions behind the spatial design, they did not even know that they were allowed to use the co-creation cabinets, to the extent of not having access to the units' keys. Furthermore, the teachers found it hard to manage the use of the ILE, being nine classes sharing the new facilities. In an attempt to activate the 


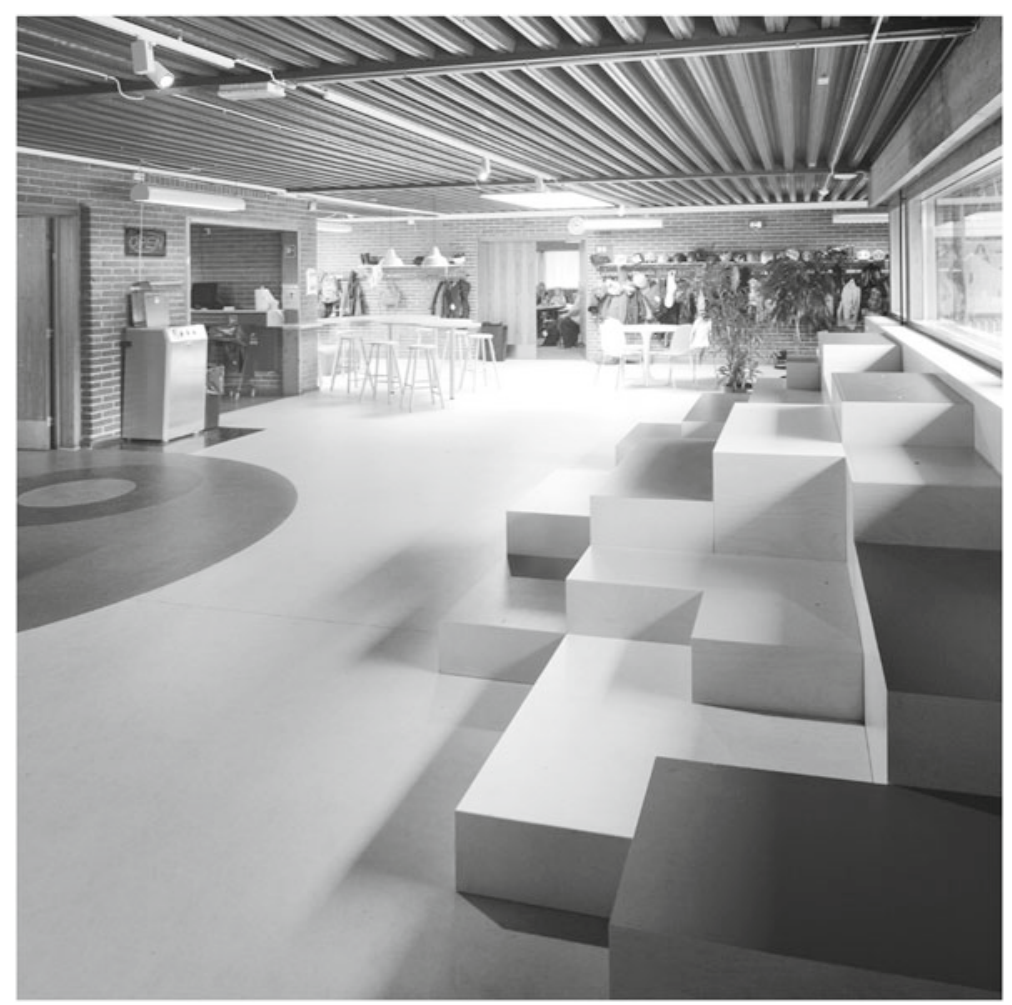

Fig. 5 Learning landscape and high table in the social zone where many learning activities can be accommodated simultaneously. Photographer: Filipa Pita, Rune Fjord Studio

ILE, the teachers were subsequently encouraged to use the space and purpose-built furniture according to intentions and to share experiences with each other on their monthly team meetings in order to inspire and create a joint work culture.

One year later, when revisiting the school, very little had changed in terms of pedagogical practices. Before redesigning the space, the teachers had fixed rules about where and how many students from each class to let out into the street-space. These rules were back in use, which meant that the ILE was not being used according to activity and affordance of the space or learner needs, but according to a teacher made division and teacher needs. The co-creation cabinets remained unused. Lackney (2008) explains this retreat to old practices as a result of the teachers not being trained in how to utilise the affordances of the space; they retreat to the safety of default practices (Cited in: Byers, Imms, \& Hartnell-Young, 2014). 


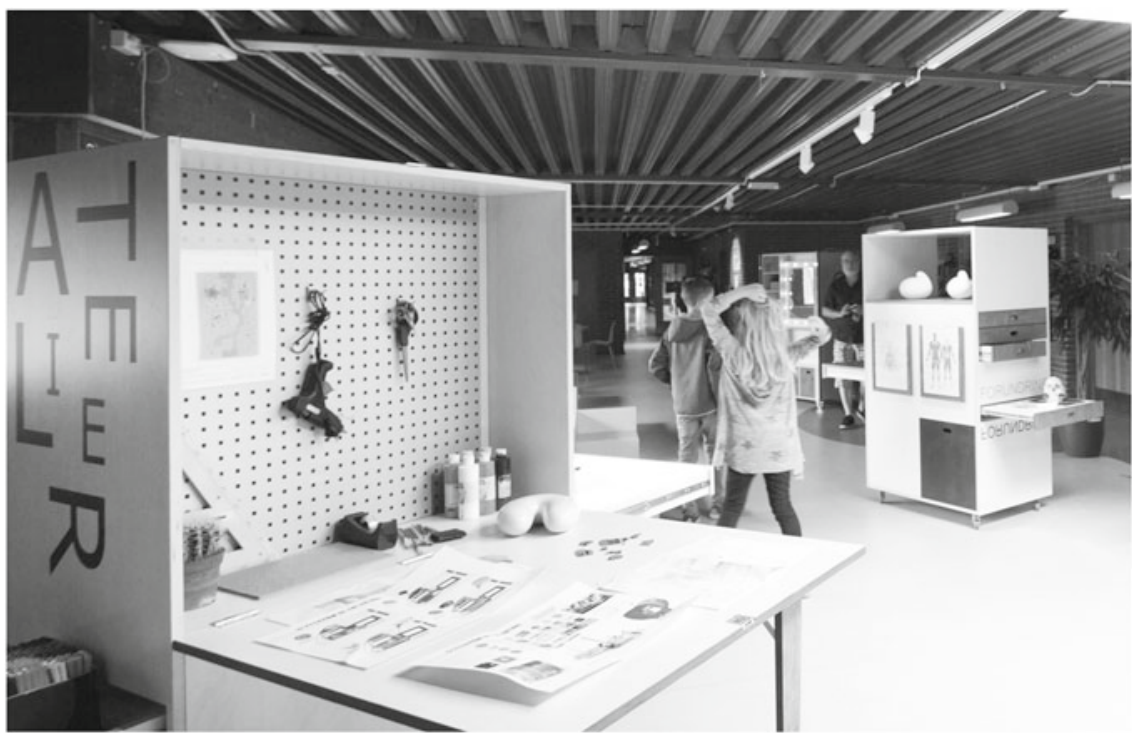

Fig. 6 Co-creation cabinets. Photographer: Filipa Pita, Rune Fjord Studio

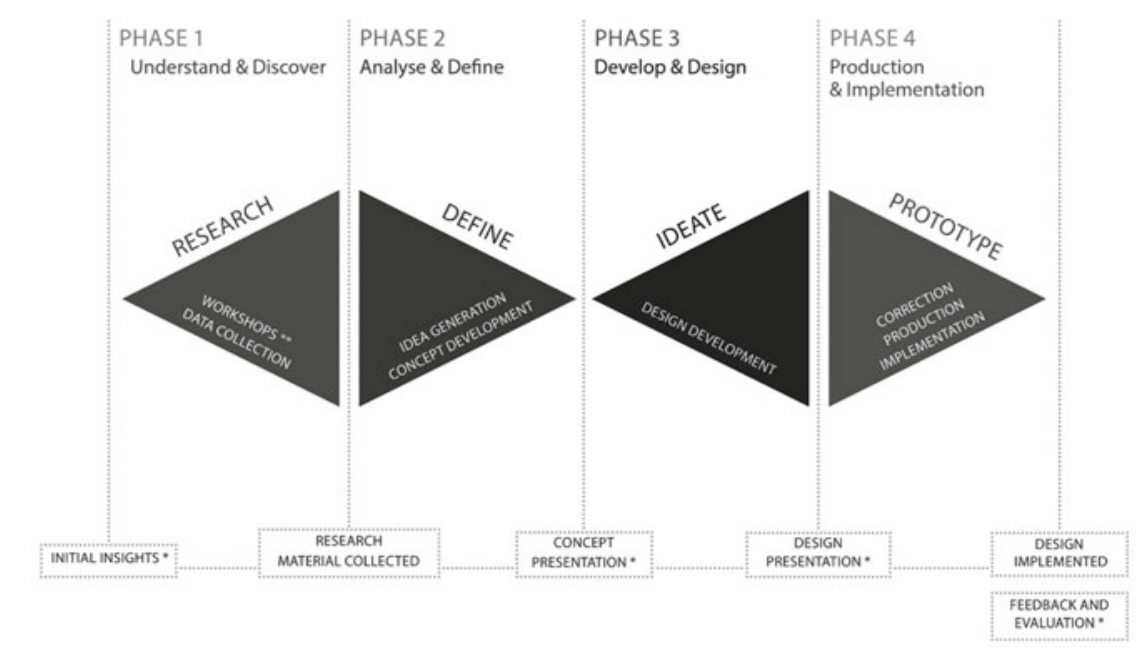

- Rune Fjord Studia, 2017

Fig. 7 A design process model in four phases by Bodil Bøjer and Rune Fjord Studio, inspired by the Double Diamond model by the British Design Council 


\section{Participatory Processes Are not Uncomplicated}

In retrospect, more effort should have been made to involve the teachers in the design process that would arguably create a common vision and perhaps facilitate the proposed alignment illustrated in Fig. 1. School management easily engaged in the process, presumably because they were the contracting authority, but it was difficult to engage the teachers. This resulted in very limited direct communication between teachers and designers. The exact reasons for this are unknown, but prospectively the challenge will be to secure the involvement of all parties during the design process of new learning environments.

The difficulty of aligning the space with the teachers' usual way of teaching indicates that the intended partnership between teaching, organisation and space did not happen during the design process. With the exception of one teacher, they were neither directly nor indirectly involved in the design process, resulting in a mismatch between design intentions and pedagogical practices, limited awareness of the intentions of the space, and a lack of ownership for the new design. While any transition from one teaching method to another is complicated, greater involvement in the design process arguably makes this transition easier and increases the chance that new designs and pedagogies correspond. Jamieson et al. (2005) stress the importance of bringing together the key stakeholders during the design process, which demands a visionary strategy for the project prior to the design phase to establish a common language and an overall understanding of the teaching strategy and different learning activities. Furthermore, they claim that the teachers should be guided into using the new types of learning spaces, which is backed up by Lackney (2008). Similarly, Blackmore et al. (2011) emphasise that new built spaces will not move teachers to innovative pedagogies unless they are prepared and provided with the necessary skills, tools and resources to change their practices.

\section{An Additional Phase to Activate the Space}

Therefore, I propose that a fifth phase, called here Delivery and Activation, is added to the design process (see Fig. 8) with the purpose of handing over and activating the project in collaboration with the users. The aim of this phase would be to match spatial possibilities with pedagogical practices. Very often, the interaction between creators and users of learning spaces abruptly ends as soon as a new design has been implemented, which leaves the users with a spatial design they might not know how to use. Without a strong leader and a common vision to push the project forward, the new design risks becoming an obstacle instead of an asset for teachers and students.

As explained earlier, the intentions of a new spatial design can be difficult to decode. During 'Delivery \& Activation' the intentions of the space are translated into actual pedagogic and learning actions, the nature of these negotiated with the users, preferably students and teachers, through a participatory process. This needs 


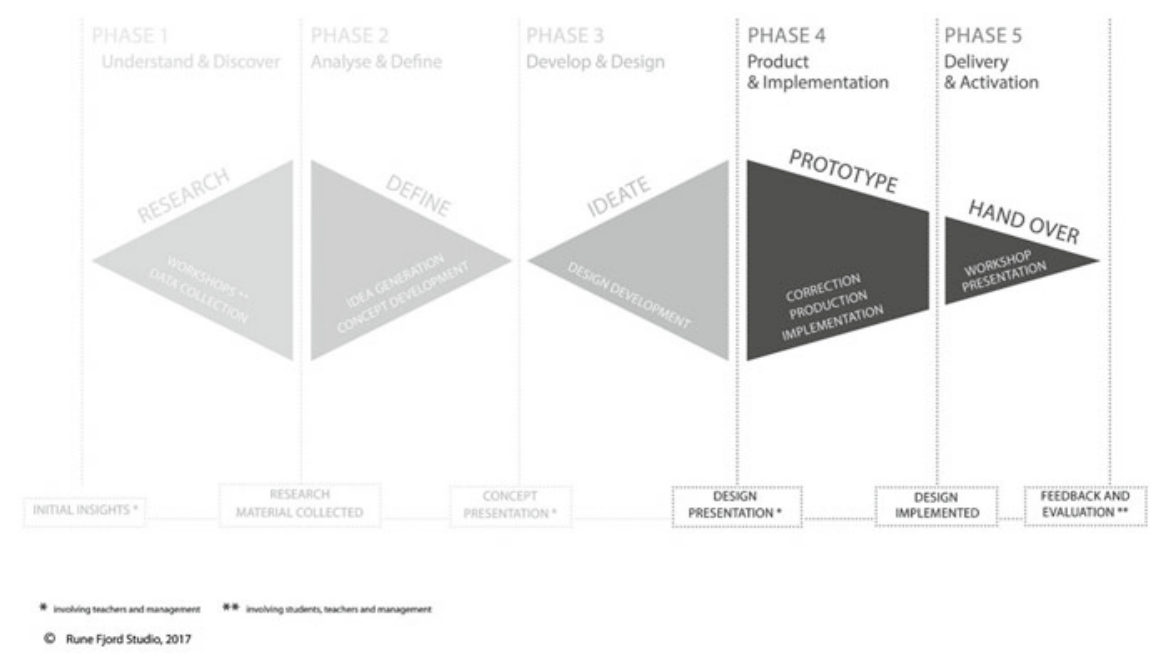

Fig. 8 The design process model with a fifth phase for delivery and activation by Bodil Bøjer and Rune Fjord Studio

to be recognised as an ongoing process where a common language and culture are established because activation is never totally finished. School design is ongoing (Blackmore et al., 2011) as it constantly develops and transforms with its users. As concluded by Higgins et al. $(2005$, p. 3)

...in a changing world no design solution will last forever, so the process of user involvement must be continually refreshed and iterated to support ongoing change. This approach has the added benefit of sustaining the meta-cognitive and motivational power of user involvement in creating the environment over time.

The actual content of this phase requires further development. It is likely there is no one way to do this, with the phase looking different in each learning space and according to different pedagogical strategies. Könings et al. (2017) propose facilitation and visual activities as a means to engage participants and encourage the sharing of ideas. In this particular research project, a participatory toolkit to help unlock the potential of ILEs based on perspectives of co-design is currently being explored in several Danish schools. The aim is to examine whether co-design methods can help create a higher level of spatial awareness and competencies, thereby potentially becoming a tool in the design process when designing new learning spaces, or a tool for activation of already existing spaces in appropriation with the users. The term co-design refers to design activities where designers and non-designers work together to develop new designs. The co-design approach has been chosen as it actively includes the participants in the design activities and has the potential to initiate a discussion about abstract pedagogical philosophical issues through a very concrete subject like e.g. the layout and experience of a learning space. Co-design differs from other discussions about possible futures by actively exploring what to 
achieve and how to achieve it in combination, using a broad repertoire of tools and techniques (Brandt, Binder, \& Sanders, 2012; Sanders, Brandt, \& Binder, 2010).

\section{Conclusions}

ILEs are being built across the world in order to foster twenty-first- century learning skills such as creativity and collaboration. In this chapter, I have proposed that in order for the ILEs to work as intended and to become a tool for improved pedagogical practices, three things must correspond: teaching (the teacher), space (the designer) and organisation (the school management). This has been exemplified in a case study at a Danish school, where a design process model was used in an attempt to engage all participants in the design process of a new ILE and through this create accordance between teaching, space and organisation to ensure a common goal: innovative learning.

Experience from the process showed that changing space did not automatically change pedagogical practices. The teachers never really participated in the design process and as a consequence, they did not know the intentions of the space nor how to use it. Based on this, I propose that, ideally, all stakeholders should be involved in the design process from the start-up phase to align teaching, space and organisation. In reality, this might not be possible due to the size of the school, budgets, time, workload and other factors. In this particular case, the teachers did not have time to participate in the design process, a product of the teachers' heavy workloads. To compensate for this, the chapter proposes that the design process should also include a process of activation after implementation of the physical design. In this phase, the users and the designers would work together to activate the new physical frames in relation to pedagogical practices. The purpose would be to match pedagogies with spatial possibilities and to provide the teachers with the necessary skills, tools and resources to change their practices in order to be able to use the space as a pedagogic tool for teaching and learning. The goal would be to help the teachers experience the space as an asset of their pedagogical practices, and not an obstacle. For this to happen, it is necessary to gain more knowledge about the interplay between the physical environment and pedagogical practices in order to create a common language and ways to activate the ILEs.

Acknowledgements Data utilised in this research was obtained in adherence to the required ethical protocol of the author's host institution. All images and diagrams are the property of the author, or the author has obtained consent to use them from the appropriate copyright owner. 


\section{References}

Beghetto, R. A., \& Kaufman, J. C. (2014). Classroom contexts for creativity. High Ability Studies, 25(1), 53-69. https://doi.org/10.1080/13598139.2014.905247.

Blackmore, J., Bateman, D., Loughlin, J., O’Mara, J., \& Aranda, G. (2011). Research into the connection between built learning spaces and student outcomes (0759406642). Retrieved from http://dro.deakin.edu.au/eserv/DU:30036968/blackmore-researchinto-2011.pdf.

Brandt, E., Binder, T., \& Sanders, E. B.-N. (2012). Ways to engage telling, making and enacting. In Routledge international handbook of participatory design (pp. 145-181). Routledge, New York.

Burke, C. (2016). Quiet stories of educational design. In K. Darian-Smith \& J. Willis (Eds.), Designing schools: Space, place and pedagogy (pp. 191-204): Routledge.

Byers, T., Imms, W., \& Hartnell-Young, E. (2014). Making the case for space: The effect of learning spaces on teaching and learning. Curriculum and Teaching, 29(1), 5-19. https://doi.org/10.7459/ $\mathrm{ct} / 29.1 .02$.

Clark, A. (2010). Transforming children's spaces: Children's and adults' participation in designing learning environments. Routledge.

Council, D. (2007). Eleven lessons: Managing design in eleven global companies-desk research report. Retrieved from http://www.designcouncil.org.uk/sites/default/files/asset/document/Ele venLessons_DeskResearchReport_0.pdf.

Craft, A. (2005). Creativity in schools: Tensions and dilemmas. USA and Canada: Routledge.

Cropley, A. J. (2001). Creativity in education \& learning: A guide for teachers and educators. Great Britain: Kogan Page.

Dovey, K., \& Fisher, K. (2014). Designing for adaptation: The school as socio-spatial assemblage. The Journal of Architecture, 19(1), 43-63.

Frayling, C. (1993). Research in art and design. In Royal College of Art Research Papers, 1.

Higgins, S., Hall, E., Wall, K., Woolner, P., \& McCaughey, C. (2005). The impact of school environments: A literature review. Retrieved from https://www.ncl.ac.uk/media/wwwnclacuk/cflat/files/ impact-school-environments.pdf.

Imms, W., \& Byers, T. (2017). Impact of classroom design on teacher pedagogy and student engagement and performance in mathematics. Learning Environments Research, 20(1), 139-152. https:// doi.org/10.1007/s10984-016-9210-0.

Imms, W., Cleveland, B., \& Fisher, K. (2016). Pursuing that elusive knowledge about what works in learning environment design. In W. Imms, B. Cleveland, \& K. Fisher (Eds.), Evaluating learning environments: Snapshots of emerging issues, methods and knowledge (pp. 3-16). Rotterdam, Netherlands: Sense Publishing.

Imms, W., Mahat, M., Byers, T., \& Murphy, D. (2017). Type and use of innovative learning environments in Australasian schools. ILETC Survey 1 (0734053819). Retrieved from https://minervaaccess.unimelb.edu.au/handle/11343/219467.

Jamieson, P., Dane, J., \& Lippman, P. (2005). Moving beyond the classroom: Accommodating the changing pedagogy of higher education. Paper presented at the Refereed Forum Proceedings of the Australian Association for Institutional Research.

Jamieson, P., Fisher, K., Gilding, T., Taylor, P. G., \& Trevitt, A. (2000). Place and space in the design of new learning environments. Higher Education Research \& Development, 19(2), 221-236. https://doi.org/10.1080/072943600445664.

Kirkeby, I. M. (2006). Skolen finder sted. KTH.

Könings, K. D., Bovill, C., \& Woolner, P. (2017). Towards an interdisciplinary model of practice for participatory building design in education. European Journal of Education, 52(3), 306-317. https://doi.org/10.1111/ejed.12230.

Lackney, J. A. (2008). Teacher environmental competence in elementary school environments. Children Youth and Environments, 18(2), 133-159.

Lawson, B. (2006). How designers think: The design process demystified. Routledge. 
Mahat, M., Bradbeer, C., Byers, T., \& Imms, W. (2018). Innovative learning environments and teacher change defining key concepts-Technical Report 3/2018. Retrieved from https://minervaaccess.unimelb.edu.au/handle/11343/216292.

Mulcahy, D., Cleveland, B., \& Aberton, H. (2015). Learning spaces and pedagogic change: Envisioned, enacted and experienced. Pedagogy, Culture \& Society, 23(4), 575-595. https://doi.org/ 10.1080/14681366.2015.1055128.

Ricken, W. (2010). Arkitektur, padagogik og sundhed. (PhD). Kunstakademiets Arkitektskole.

Sanders, E., Brandt, E., \& Binder, T. (2010). A framework for organizing the tools and techniques of participatory design. Paper presented at the Proceedings of the 11th biennial participatory design conference.

Schön, D. (1983). The reflective practitioner. Great Britain: Basic Books.

Tanggaard, L. (2014). A situated model of creative learning. European Educational Research Journal, 13(1), 107-116. https://doi.org/10.2304/eerj.2014.13.1.107.

Bodil Bøjer (Denmark), PhD, is a Research Fellow at The Royal Danish Academy of Fine Arts, School of Design. Her research examines the relationship between learning space design and pedagogical practices from a design perspective with a particular focus on participatory design processes, methods and tools. Bodil completed her Industrial PhD, 'Unlocking Learning Spaces - an examination of the interplay between the design of learning spaces and pedagogical practices' in 2019, where she used a Research through Design approach in several design experiments in collaboration with the Danish design agency Rune Fjord Studio and The Royal Danish Academy of Fine Arts, School of Design. She is a member of the European research network Drapes (Design, Research and Practice in Educational Spaces) and currently involved in the European research project, $\mathrm{CoReD}$ (Collaborative Redesign with Schools). Moreover, Bodil holds an MA in Art History and Aesthetics and Culture and has 10+ years of practical experience working with spatial design.

Open Access This chapter is licensed under the terms of the Creative Commons Attribution 4.0 International License (http://creativecommons.org/licenses/by/4.0/), which permits use, sharing, adaptation, distribution and reproduction in any medium or format, as long as you give appropriate credit to the original author(s) and the source, provide a link to the Creative Commons license and indicate if changes were made.

The images or other third party material in this chapter are included in the chapter's Creative Commons license, unless indicated otherwise in a credit line to the material. If material is not included in the chapter's Creative Commons license and your intended use is not permitted by statutory regulation or exceeds the permitted use, you will need to obtain permission directly from the copyright holder. 